\title{
The Determination of Reduction Ratio Factor in Homogeneous Soil-Slope with Finite Element Double Strength Reduction Method
}

\author{
Xiaoyong Jiang ${ }^{1,2, *}$, Zegen Wang ${ }^{1}$, Lianyong Liu ${ }^{3}$, Zhiping Zhou ${ }^{4}$ \\ ${ }^{1}$ School of Civil Engineering and Architecture, Southwest Petroleum University, Chengdu 610500, China \\ ${ }^{2}$ China Petroleum Pipeline Engineering Corporation, Langfang 065000, China \\ ${ }^{3}$ Petro China Taizhou Company Limited, Xinghua 225721, China \\ ${ }^{4}$ Sinopec Geophysical Corporation--Jiangsu Branch, Yangzhou 225000, China
}

\begin{abstract}
Even though there exist lots of documents on Finite Element Strength Reduction Method, cohesion and internal friction angle in these materials are reduced through the same reduction factor, which fails to reflect either of their safe reserving quality or the quality to precisely match slope failure process and mechanism. As is known, the exterior angle circumcircle yield criterion DP1 of the generalized Mises would cause larger slope stability factor in slope stability analysis, whereas inscribed circle yield criterion DP4 of the generalized Mises has higher precision for the plane strain problem. Since the ANSYS has only DP1 criterion, considering the DP4 yielding criterion's higher precision than DP1 in plane strain, the author first converts DP4 to DP1 that can be accepted by ANSYS, and then conducts separate reductions to cohesion and internal friction angle with different reduction proportionality factors according to double reduction factor method, and analyzes the calculation results afterwards. The results after analysis show that when cohesion and internal friction angle are reduced by reduction proportionality factor $\mathrm{K}=1.75$, the failure characteristic of slope and attenuation specification of strength parameter match well to the real situation Therefore, reduction proportionality factor $\mathrm{K}=1.75$ of cohesion and internal friction angle is typically recommended in homogeneous soil-slope.
\end{abstract}

Keywords: Finite Element Double Strength Reduction Method, Double Reduction Proportionality Factor, Homogeneous Soil-Slope.

\section{INTRODUCTION}

In traditional limit equilibrium [1], cohesion $C$ and internal friction angle $\varphi$ of geotechnical materials strength parameters were mainly reduced by the same safety factor in slope stability analysis. In the current finite element single strength reduction method, these two parameters were also reduced by the same reduction factor. However, geotechnical materials possess not only bond strength but also frictional strength, besides, the attenuation speed and its extent of the two are inconsistent in the process of intensity attenuation [2]. Therefore, if adopting the traditional single reduction factor, neither cohesion nor internal friction angle can be fully discovered. Generally speaking, the decay rate of the cohesion is greater than the internal friction angle, also, the action mechanism and the function order are not identical, and so two reduction factors are undoubtedly a must. The method of separate reductions to the two strength parameters is called double strength reduction [3]. The basic principle of

*Address correspondence to this author at the School of Civil Engineering and Architecture, Southwest Petroleum University, Chengdu 610500, China; Tel: 86-13880440514; 86-13668221158; E-mails: zegen01@126.com; 103531764@qq.com the double strength reduction is to make the double strength parameters' change after reduction more corresponding with slope instability process and the actual strength characteristics. Hence, this method can more accurately reflect each safety reserves of cohesion and internal friction angle of $C$ and $\varphi$, making it of greater application value in practical engineering [4]. However, in the slope sliding process, how do the cohesion and internal friction angle process attenuation change? Which would firstly come into play and to what extent for both of them? What is the mechanism of action? Which reduction method should cohesion and internal friction angle adopt to conform better to the real situation? At present, there exists insufficient literature in this regard. However, the determination of the reduction ratio factor is the key to the double reduction factor method.

\section{THE VARIATION CHARACTERISTICS OF CO- HESION AND INTERNAL FRICTION ANGLE IN THE PROCESS OF SLOPE INSTABILITY}

Slope failure can generally be divided into three types [5]: suddenly sliding type, progressive failure type and resurrection creep type. This paper mainly focuses on studies of the progressive failure of the soil slope. 
It is inevitable to form a shear zone when the soil slope sliding and the shear zone are closely associated with the strain softening characteristics of the soil. Chinese geotechnical expert, academician SHEN Zhujiang classified the strain softening into three types [6]: Decompression softening, Dilatancy softening and Damage softening. When the strain is small, the components of cohesion and dilatancy can fully work, so the soil attains greater shear strength. When the strain exceeds certain extent, the cohesion of the soil will be quickly destroyed; shearing dilatancy components will gradually fade away; and soil strength will significantly decrease. If sliding zone and sliding body are in progressive failure, the previous close occlusal relation will be destroyed, and flat particles' shearing directional arrangement will cause strength reduction of internal friction angle and loss of cohesion developed by cementation [7]. In the whole process, the degree of cohesion loss is larger than the internal friction angle.

Geotechnical materials are of double strength, whose [8] combined action will determine the slope stability. The sample test results of direct shear showed that [9]: When the slope horizontal displacement is small, the cohesion function starts first, and the shear strength increases gradually. With the increase of the displacement, friction begins to play a larger and larger role until it reaches to the limit. Therefore, in the process of soil slope instability [10], the cohesion should first come into full play and with the increase of strain the friction resistance can begin to work. Based on the analysis above, in the analysis of double reduction factor, we should adopt the method in which cohesion reduction is greater than the internal friction angle.

\section{YIELD CRITERION TRANSFORMATION}

In the ANSYS program, the yield criterion adopts the exterior angle circumcircle DP1 criterion. However, the safety factor calculated in this way tends to be larger than the actuality. Therefore, this arctic uses DP4 criterion under the plane strain condition. The calculation process of finite element double strength reduction method can be concluded into the following two steps:

(1) Standards conversion from DP4 to DP1: Converting the geotechnical original cohesion and internal friction angle of DP4 criteria into DP1, the converted cohesive strength and friction angle can directly be substituted into the ANSYS program. It is important to note that the safety factor should be equal to 1 , when we convert DP4 to DP1. Namely, it is the transformation only between the criterions without strength reduction. The conversion process is as follows [11]:

Under the association rule, the $\alpha, k$ of DP4 yield criterion matching plane strain Mohr-Coulomb are:

$$
\alpha_{1}=\frac{\sin \varphi_{1}}{\sqrt{3\left(3+\sin ^{2} \varphi_{1}\right)}}
$$

$$
k_{1}=\frac{3 c_{1} \cos \varphi_{1}}{\sqrt{3\left(3+\sin ^{2} \varphi_{1}\right)}}
$$

Given that the ANSYS only provides the exterior angle circumcircle DP1 criterion, whose corresponding $\alpha, k$ are:

$$
\begin{aligned}
& \alpha_{2}=\frac{2 \sin \varphi_{2}}{\sqrt{3}\left(3-\sin \varphi_{2}\right)} \\
& k_{2}=\frac{6 c_{2} \cos \varphi_{2}}{\sqrt{3}\left(3-\sin \varphi_{2}\right)}
\end{aligned}
$$

Making $\alpha_{1}=\alpha_{2} 、 k_{1}=k_{2}$, we got the followings:

$$
\begin{aligned}
& \alpha_{1}=\frac{\sin \varphi_{1}}{\sqrt{3\left(3+\sin ^{2} \varphi_{1}\right)}}=\frac{2 \sin \varphi_{2}}{\sqrt{3}\left(3-\sin \varphi_{2}\right)}=\alpha_{2} \\
& k_{1}=\frac{3 c_{1} \cos \varphi_{1}}{\sqrt{3\left(3+\sin ^{2} \varphi_{1}\right)}}=\frac{6 c_{2} \cos \varphi_{2}}{\sqrt{3}\left(3-\sin \varphi_{2}\right)}=k_{2}
\end{aligned}
$$

Making simultaneous equations with (5) and (6), we got:

$$
\begin{aligned}
& \varphi_{2}=\arcsin \frac{3 \sin \varphi_{1}}{\sin \varphi_{1}+2 \sqrt{3+\sin ^{2} \varphi_{1}}} \\
& c_{2}=c_{1} \times \frac{\tan \varphi_{2}}{\tan \varphi_{1}}
\end{aligned}
$$

The cohesion and internal friction angle calculated by (7) and (8) were the one converted by DP4 criterion that could be directly applied to ANSYS program.

(2) Reducing the converted cohesion and internal friction angle by their respective reduction factors and substituting them into FEM program, and calculating until the result is non-convergence. By this time, each corresponding safety factor was just the one desired after calculation, and the ratio between the two was the reduction ratio.

\section{EXAMPLES AND ANALYSIS}

Example: Models were simplified to the plane strain problem. The height of the homogeneous soil-slope was $20 \mathrm{~m}$ and the slope inclination angle was $30^{\circ}$. The boundary conditions were: The restraint of the model side was horizontal in $\mathrm{X}$ direction and the base was fixed constraint of $\mathrm{X}$ and $\mathrm{Y}$. The 8-node PLANE82 node was used in soil, whose adaptability to irregular grid was better. The calculation used DP4 criterion and non-associated flow rule was adopted. Geotechnical material parameters were: cohesion $=42 \mathrm{kPa}$, internal friction angle $=17^{\circ}$, bulk density $=20 \mathrm{KN} / \mathrm{m}^{3}$, elastic modulus $\mathrm{E}=1.0 \times 10^{5} \mathrm{kPa}$ and Poisson's ratio $\mu=0.3$. The 
ANSYS calculation model and grid partition model were as shown in Figs. (1 and 2).

For heterogeneous soil-slope, the attenuation of cohesion and internal friction angle was gradual, so it belonged to the progressive failure type. From the analysis above, we can get in the whole process the loss of cohesion was greater than that of internal friction angle. Consequently, in the analysis of double reduction factor method, the reduction factor of cohesion should be larger than that of the internal friction angle, that is, the reduction ratio factor $(\kappa)$ of cohesive and internal friction angle should be larger than 1 . If we didn't reduce the internal friction angle in the calculation, when slope got instable, the reduction factor of the cohesion should be 2.66 times that of internal friction angle, that is, the reduction ratio factor should be lower than 2.66. Therefore, the range of the reduction ratio factor should be $1<$ $\kappa<2.66$. Here the value in this range was calculated every 0.25 times, and the calculation results were shown in Table 1.

In the second row of table 1 above, when $F_{C}=1.00 F_{\varphi}$, finite element single strength reduction method was adopted. From Table 1 above, we could draw the conclusions that: if the different reduction ratio factors in this slop were adopted, and when the slop reached to the limit equilibrium, the corresponding strength parameters would have a significant difference. In order to easily select a reasonable ratio factor, Fig. (3) would show the plastic strain diagram inside the slope of different ratio factors.

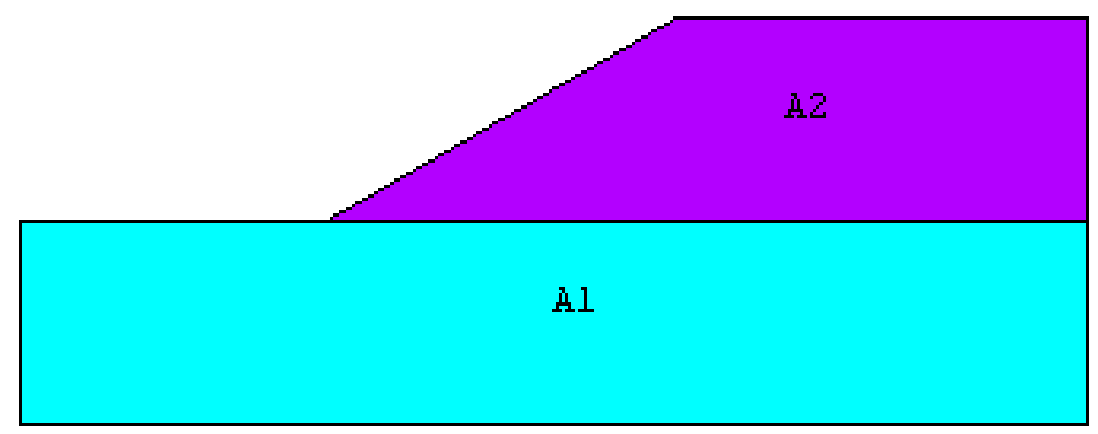

Fig (1). Finite element computing model.

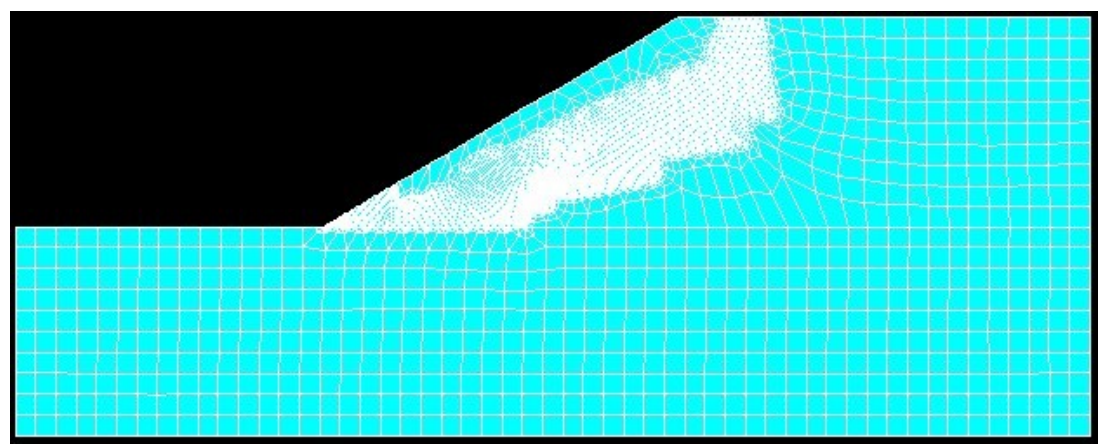

Fig (2). Finite element grid partition model.

Table 1. Respective Reduction Factor and Safety Factor of Cohesion and Internal Friction Angle with Finite Element Double Strength Reduction Method

\begin{tabular}{|c|c|c|c|c|c|}
\hline Reduction Method & $F_{C}$ & $F_{\varphi}$ & Cohesion(Pa) & $\begin{array}{c}\text { Internal Friction } \\
\text { Angle }\end{array}$ & Safety Factor $F$ \\
\hline$F_{C}=1.00 F_{\varphi}$ & 1.497 & 1.497 & 21736.48 & 8.9912 & 1.497 \\
\hline$F_{C}=1.25 F_{\varphi}$ & 1.677 & 1.341 & 19409.19 & 10.0155 & 1.509 \\
\hline$F_{C}=1.50 F_{\varphi}$ & 1.863 & 1.242 & 17466.19 & 10.8001 & 1.553 \\
\hline$F_{C}=2.00 F_{\varphi}$ & 2.210 & 1.105 & 14723.76 & 12.0981 & 1.658 \\
\hline$F_{C}=2.25 F_{\varphi}$ & 2.388 & 1.061 & 13627.97 & 12.5825 & 1.724 \\
\hline$F_{C}=2.50 F_{\varphi}$ & 2.554 & 1.022 & 12740.61 & 13.0534 & 1.788 \\
\hline
\end{tabular}




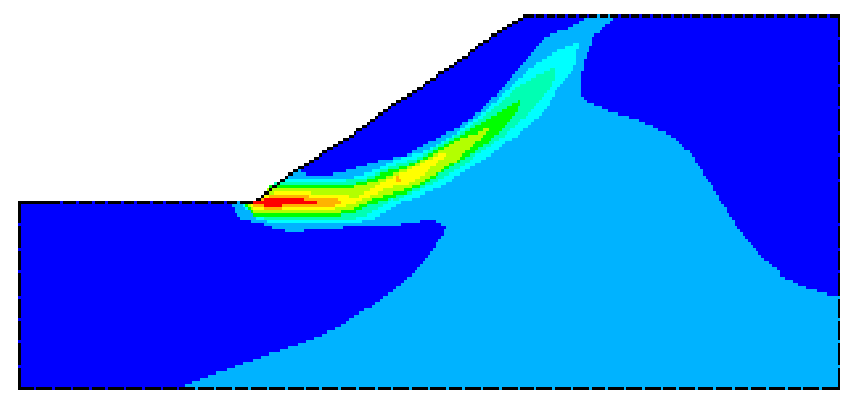

(a) $\boldsymbol{K}=1.75$

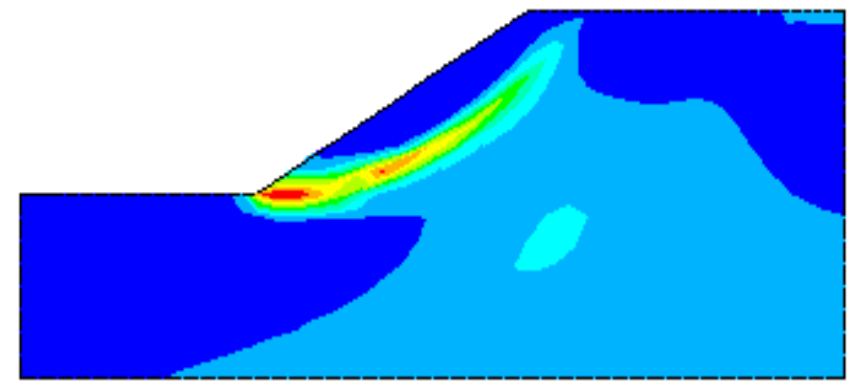

(c) $\boldsymbol{K}=2.25$

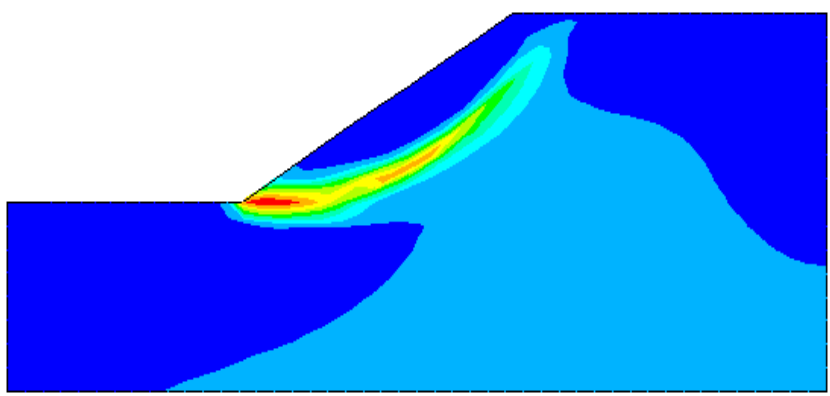

(b) $K=2.0$

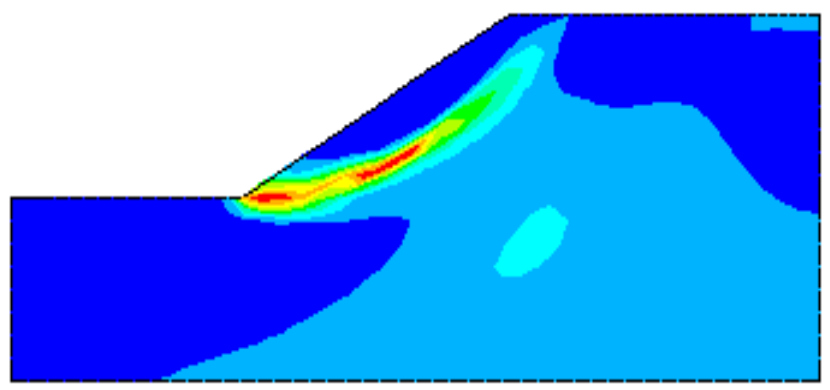

(d) $K=2.5$

Fig. (3). The plastic strain diagram inside the slope of different reduction factors.

From the comparison of Fig. (3) we could easily find that: (1). With the increase of the reduction factor, the position of the slope potential sliding surface was shallower, steeper, and closer to the ground. (2) With the increase of the reduction factor, the range of the plastic area inside the slope was tended to increase gradually. In (c) of the drawing, there was a circle in the slope, in which the stress was bigger than the corresponding position of $b$. It also suggested that the inner stress of the slope gradually increased with the increase of the factor. (3) From the four figures, we could see that the red area was moving in the direction of the slope toe to slope crest, that is, the maximum stress of the slope was transferring from the slope toe to the slope crest slowly.

For soil slope, the intensity attenuation characteristic usually showed progressive failure. In the failure process, cohesion would quickly be destroyed and the internal friction would generally reduce by $2^{\circ}$ or so; moreover, the biggest stress area of the slope would be in the shear outlet of the slope. Combining Table 1 and Fig. (3), we could reach the conclusion: when ratio factor $\kappa=1.75$, the internal friction angle decreased by $2.35078^{\circ}$ and the cohesion dropped by $16578.99(\mathrm{pa})$, which totally conformed to the progressive failure progress of the soil slope that was obtained by previous analysis. Therefore, for homogeneous soil-slope, this paper suggests using ratio factor $\kappa=1.75$ for reducing the geotechnical materials.

\section{CONCLUSIONS}

Generally speaking, for reducing the geotechnical materials the attenuation of homogeneous soil-slope was in progressive failure. The above analysis indicated: firstly, for slope failure process and mechanism, double reduction factor method was more grounded in reality than the reduction by the same reduction factor; secondly, double reduction pro- portionality factors did better in revealing information like areas hiding weak side slope, the depth of potential sliding slope, inner stress of the slope and the law of strain, thus offered theoretical guidance to harness side slopes. In conclusion, reduction proportionality factor $\kappa=1.75$ of cohesion and internal friction angle was highly recommended in analyzing homogeneous soil-slope.

\section{CONFLICTS OF INTEREST}

The authors confirm that this article content has no conflicts of interest.

\section{ACKNOWLEDGEMENT}

None declared.

\section{REFERENCES}

[1] W. Gongxian, W. Yingxian, and M. Huimin, 100 cases of landslide prevention. China Communications Press: Beijing, 2008.

[2] G. L. Jiang, and J. P. Magnan, "Stability analysis of embankments: comparison of limit analysis with methods of slices". Geotechnique, vol. 47, pp.857-872, 1997.

[3] X. U. Bangdong, Landslide Analysis and Prevention. China Railway Publishing House: Beijing, 2001.

[4] Q. Zaruba, and V. Mencl, Landslide and its contro. China Building Industry Press: Beijing, 1974.

[5] Z. Ying-ren, C. Zhuyu, W. Gongxian, and L. Tianqing, Enginering Treatment of slope and landslide. China Communications Press: Beijing.

[6] Z. Ying-ren, S. Zhujiang, and G. Xiaonan. The generalized plasticity theory-geotechnical plastic mechanics principle. China Building Industry Press: Beijing, 2002.

[7] Z. Ying-ren, Z. Shangyi, L. Anhong, and T. Xiaosong, FEM Limit Analysis and Its Application in Slope Eenineering. China Communications Press: Beijing, 2011.

[8] T. Fen, and Z. Ying-ren, "Slope Stability Analysis Based on Two Safety Factors". J. Highway Transp. Res. Dev. vol. 25, no. 11, pp.39-45, 2008. 
[9] Z. Ji-tao, and L. Yun-an, "Application of Double Strength Reduction to High Slope Stability Analysis", Saf. Environ. Eng., vol. 19, no. 6, pp. 325-331, 2012.

[10] T. Fen, Z. Yingren, and Z. Shangyi, "Discussion on Two Safety Factors for Progressive Failure of Soil Slope", Chin. J. Rock Mech. Eng., no. 7, pp. 1402-1407, 2007.
[11] Z. Cai gen, and Z. Bin, "Transformation of Slope safety factor based on different Drucker-Prager criteria", Rock Soil Mech., vol. 32, no.12, pp. 3751-3755, 2011.

Received: March 14, 2013

Revised: August 17, 2013

Accepted: August 19, 2013

(C) Jiang et al.; Licensee Bentham Open.

This is an open access article licensed under the terms of the Creative Commons Attribution Non-Commercial License (http://creativecommons.org/licenses/ by-nc/3.0/) which permits unrestricted, non-commercial use, distribution and reproduction in any medium, provided the work is properly cited. 